\title{
DESIGNING WITH LIGHT AND MEANING: A DESIGN PROJECT FOR LUMINARIES INSPIRED BY "THE LITTLE PRINCE BY ANTOINE DE SAINT EXUSPERY"
}

\author{
Luis Fernando PATIÑO SANTA \\ Universidad EAFIT, Medellín, Colombia
}

\begin{abstract}
Teaching to design is a challenge in this era. Motivating the students to learn a systematic design process, designing exercises for them to develop basic competences as Product Design Engineers (PDE) besides that, to include the teaching of values and integrity constitute big challenges in a first year study. This paper exemplifies the union of these two thoughts: how to teach design motivating the student to learn and how to reflect about the human values of the classroom. A pedagogic strategy is formulated and developed in a basic course. Design a standing luminaire inspired by the work of universal character like the Little Prince by Antoine de Saint Exuspery. This ongoing project shows how the students are guided to understand their discipline in a design process integrating thought, feeling and doing with an ethics reflection designing with light and meaning.
\end{abstract}

Keywords: Motivation, integrity, learning, luminaire, design

\section{INTRODUCTION}

Awaking the motivation in students to begin to design in the first semesters is a difficult and challenging issue for the teachers in PDE programme at EAFIT university. They must find an inspiring motive for the students to learn to find solutions to a design problem, besides that they must design pedagogic strategies for the students to begin developing their own abilities as PDE and understand the meaning of their profession through a challenging and motivating exercise.

In this context, formulating a design exercise in a basic cycle should balance aspects such as level of complexity, motivation, capacity to execute, integration of disciplines and auto reflection when designing - metacognition- additionally this reflection should question them about the importance to design understanding the human values. However, integrating all these factors in a design course is not common in the first year. In general, the teaching of human values in design has been addressed from three dimensions; ontological, epistemological and practical dimension [1]. Moreover, this topic is complex, and it is mostly approached through extracurricular activities, but not as part of a central design course.

This article describes an ongoing project that aims to tackle the afore-mentioned challenges. For this purpose, students from the first year of the PDE programme face the challenge of designing a standing luminaire, taking as reference the book by Antoine Saint Exuspery, The Little Prince. Standing luminaires are chosen, as their design involve different areas of learning such as visual representation, the development of the developments of models and the application of design methodology to reach a result.

The students choose a character, paragraph or human value found in the book The Little Prince by Antoine de Saint Exuspery as a concept to start to design. The idea was to reflect about this concept to development the project. The Centre of Integrity of EAFIT University is linked to the development of the exercise searching for an education from the being [2], allowing students who approach the theme of values by taking the Little Prince's book as inspiration to design. The final lamps were exhibited to the university community in a cultural and academic event called the light is $O N$ where music, visual experience and the staging of the projects are combined. This article presents look the first results to analyse if the students were able to reflect about the values from the book represented in the luminaires. 


\section{METHODOLOGY}

In this seven-week project, the students are faced with a lighting challenge: they must design a $1.60 \mathrm{~m}$ high standing luminaire individually. They must follow a design methodology called: "a step by step inner journey", because the lamp project opens possibilities for the students to select a topic that drives them as individuals. Additionally, this object requires the student to demonstrate knowledge about materials, structures, assemblies, manufacturing processes and functionality. Its difficulty can be addressed in a second semester of the bachelor and thus involves different areas of learning such a visual representation, the development of models, the application of physical principles, and a design methodology to reach a final result. [3]. The following is an explanation of the methodology and all the figures are taken from the book Designing with Light and Meaning, published by Editorial EAFIT in 2018 that summarise the experience.

Stage 1: presentation of the brief and introduction to the exercise. The students had to approach to Saint Exuspery's literary work and had to choose a chapter, concept or phrase that was related to a past or present personal experience. They had to do a mind mapping exercise based on the concept they would work with. In addition, the challenges in this week were to learn how to draw lamps and understanding the principles of how to design a lamp [4]. The figure 1 shows this teaching and learning strategy summarised.

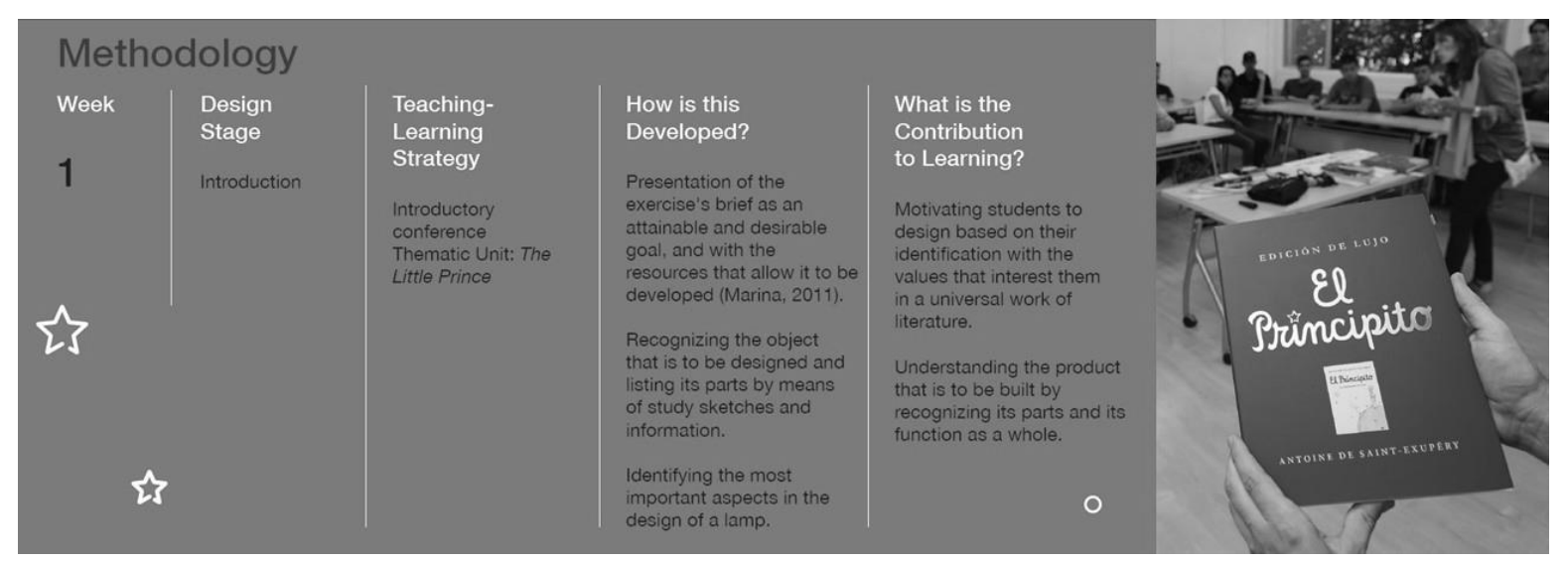

Figure 1. Description of the design stage.

Stage 2: defining the concept: bonding with what is essential. The mind mapping tool helps to generate concepts in the initial stage of ideas. See figure 2. In this case, a radial format was used to generate an optical vocabulary that allows the exercise to be developed. The students chose different concepts like friendship, fear, pain, love or main characters from the book to represent values or virtues. Once the students found inspiration to design the luminaire, they had to developed fifteen proposal of their ideas and select the best one according to the brief.

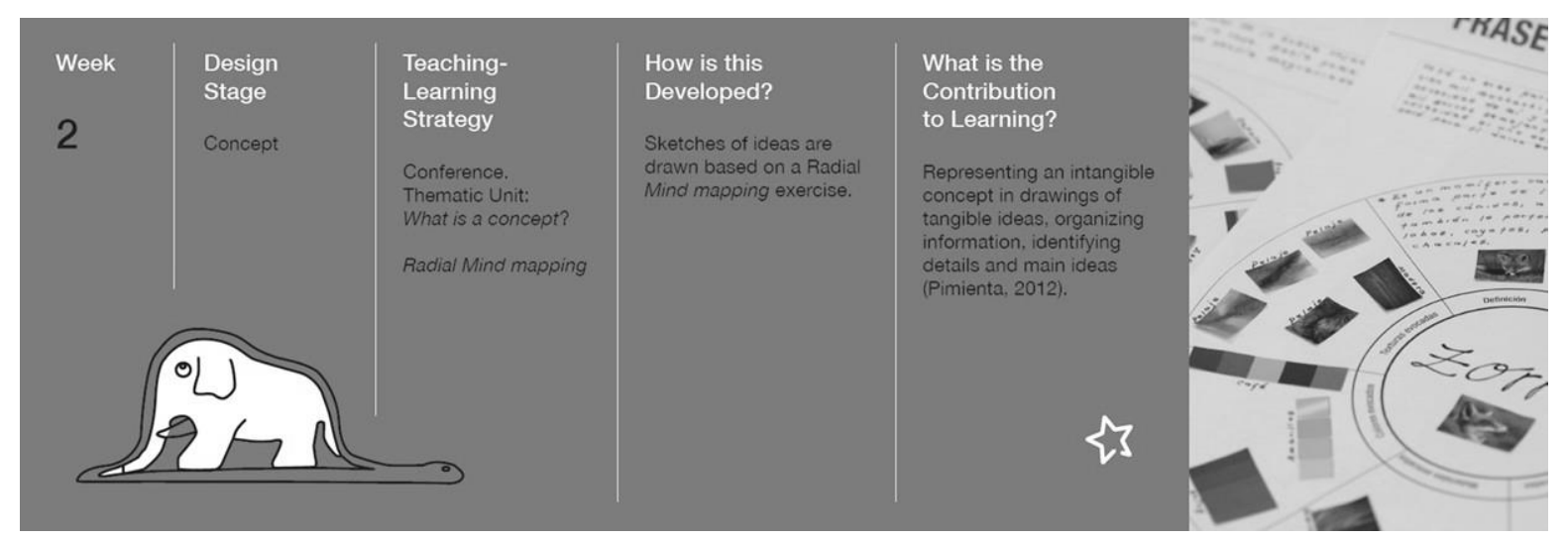

Figure 2. Description of stage 2 and example of the radial mapping

Stage 3: Development of ideas: relying on techniques and materials. The students participated in jewellery, origami and wood workshops outside the classroom during this week. They had the 
opportunity to learn about working in brass, paper folding, -origami- and wood assembly. These materials simplified the final construction and supported the materialisation of the concepts. Spheres, flowers and stars shapes were some forms that emerged from the concepts explored by the students folding paper and based on the Little Prince. The brass sheets were worked to translate the characters from the book to the lamps to complement the detailed design and made each project unique. See figure 3. The wood workshop was used to help to the students to integrate the assemblies like angled joints with tabs, boxes and spikes and the use of dowels into the final design. Besides, another method like strings, 3M high strength adhesive tapes, Velcro and fasteners were used to achieve firmness and resistance and highlight an aesthetic value through them.

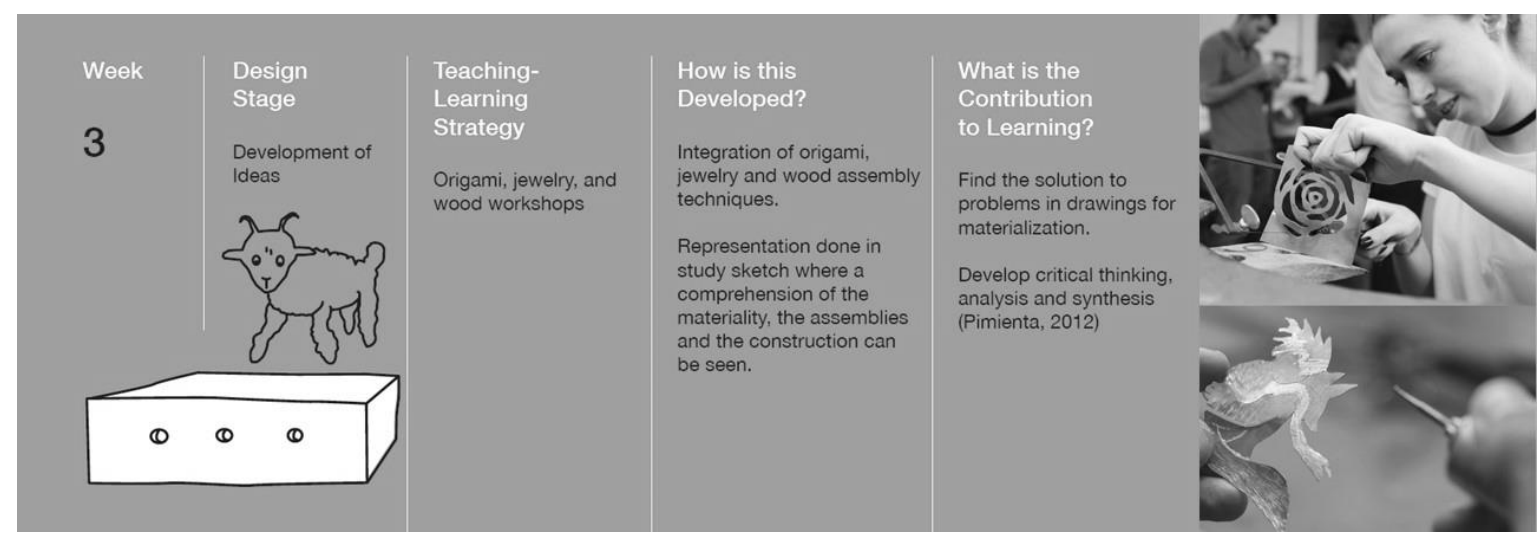

Figure 3. Description of stage tree and some examples of jewellery workshop

Stage 4: embodiment: light as a design tool. Light plays a decisive role in the design of each luminaire as it forms the essence of the project and is addressed on the most important aspects of the exercise. The source, the type of light generated, the orientation and reflection are factors that make each luminaire unique and generate different atmospheres in a space. In this week, we introduced the basic concepts as types of light sources, types of lighting, the elaboration of a simple circuit. The students had already developed a 1:2 scale model and the lighting expert answered questions about how to integrate the circuit in each project. See figure 4.

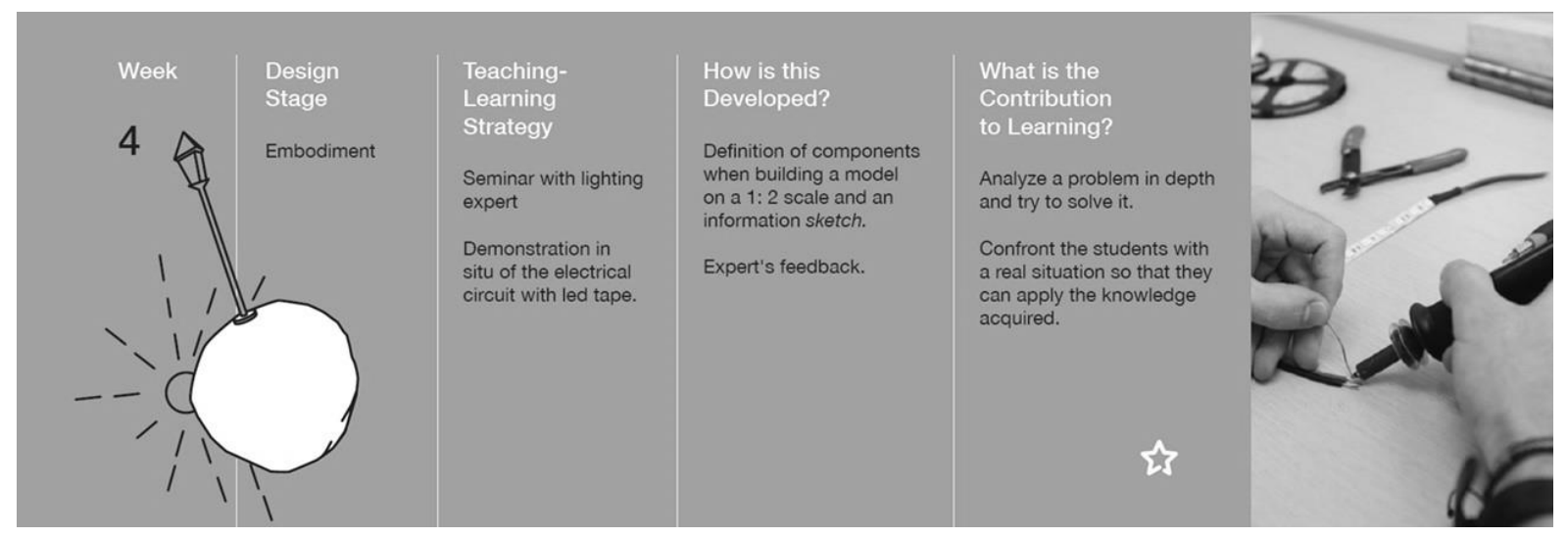

Figure 4. Embodiment stage and seminar with lighting expert

Stage 5: detailed design: scale and proportion. At this stage of the exercise, the students have already defined the concept of the luminaire, the circuit and how to integrate it, and how they are going to build it. However, they need an extra tool to define details: blueprints in millimetre paper in scale 1:1. They draw the front or side view that shows the most information about the product, applying attention to detail in each section change. This process is presented in figure 5. The aim of this stage is to use just the right material at the right point, avoid ornaments and unnecessary stuff and remember that everything has a purpose in design. 


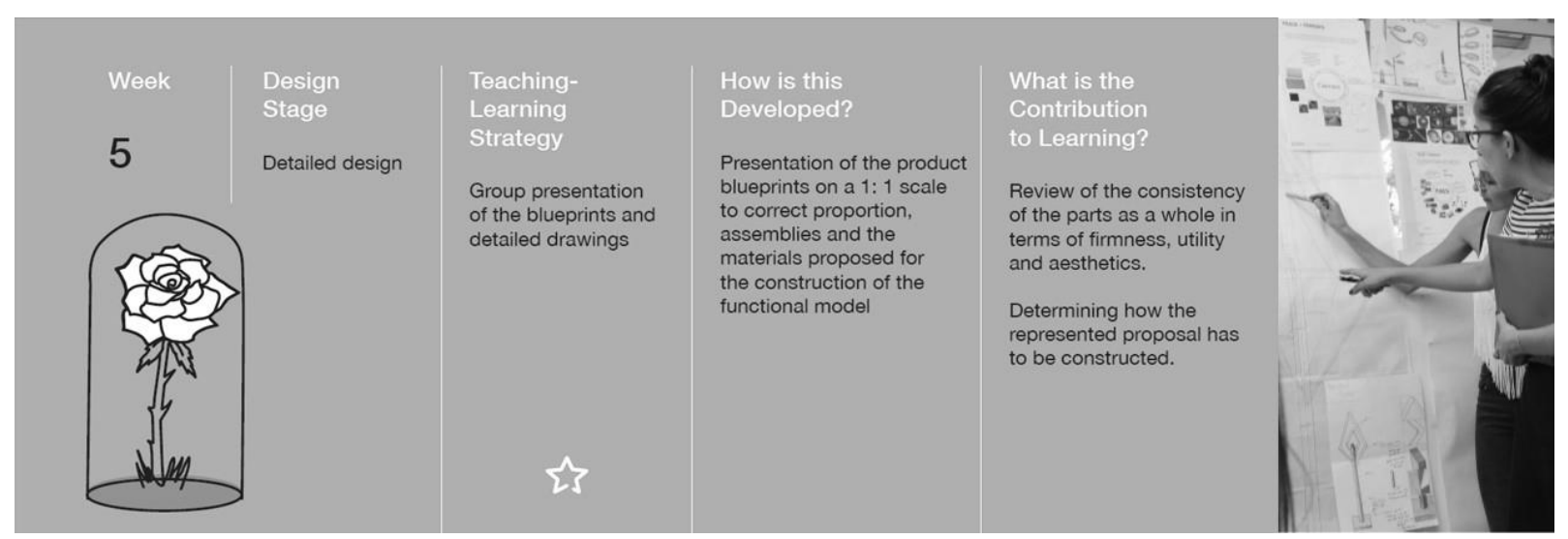

Figure 5. The correction section during the fifth week

Stage 6: materialisation: building, verifing and evaluating. This luminarie project involved carrying out a design processes from star to finish. The student's ability to design and manufacture a functional model was tested for the first time in the major. The students had to assemble different materials, a circuit and several other elements which comprised the whole product. After having finished the manufacturing processes of the luminaire, the evaluation is done. The following aspects as taken into account: integrity, firmness, usefulness and beauty. This stage is presented in figure 6.

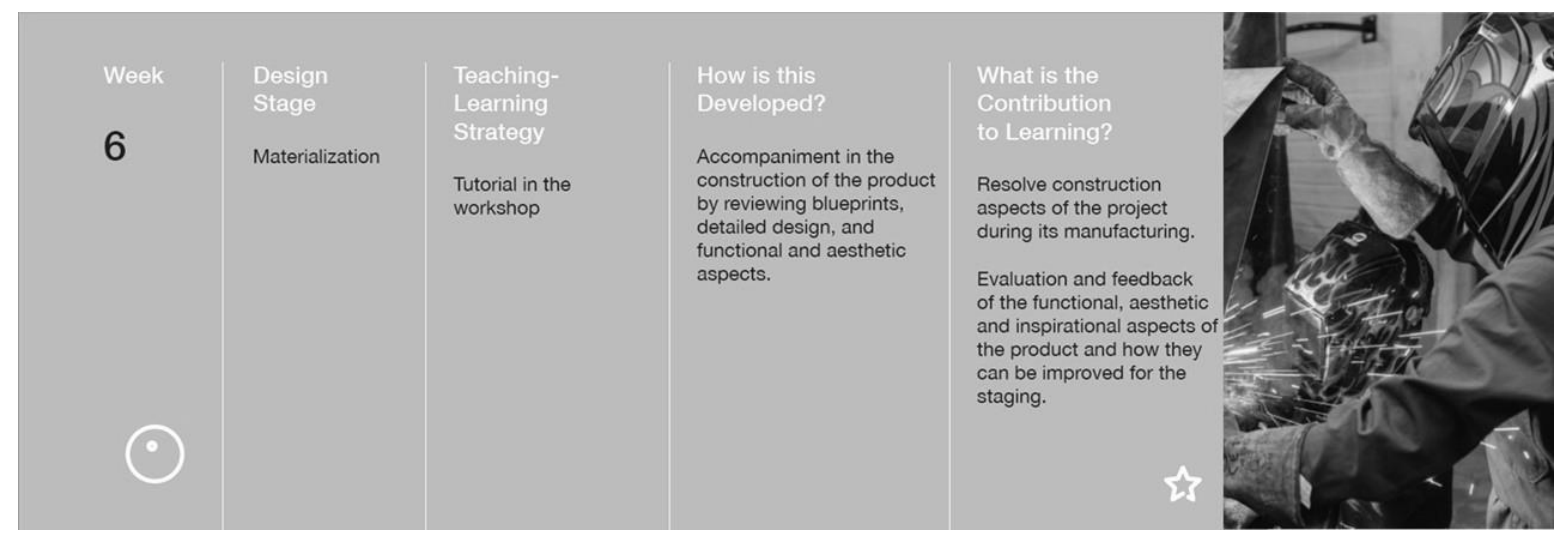

Figure 6. Stage of materialisation

Stage 7: staging the light is ON. Version IV. This luminarie project has been present since 2016 and at the end of each semester the results are displayed in a event called The light is on. The event integrates music, visual experience and the staging of the work developed by the students. The event was created with the idea of motivating the students to have the university community participate in their design proposals.

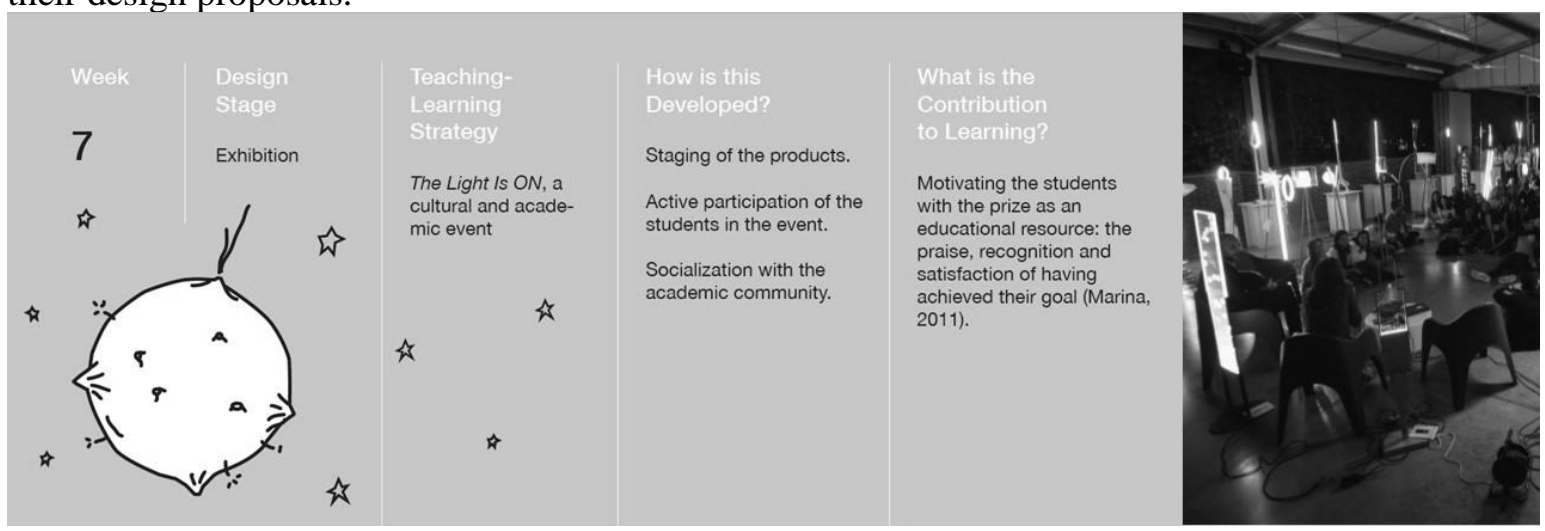

Figure 7. The light is on, a cultural and academic event 


\section{RESULTS}

The exercise was enriching, because it contributed the students to understand design discipline. In terms of mechanical and structural foundations, the exercise allowed the student to understand the materials and processes involved in the construction of firm luminaire at the basic level. Most of the lamps were stable.

In terms of ideas and concepts, the students developed a concept and evaluated it in terms of final result. The intrisec motivation of the students was a leimotiv to do a task "in their own interest, for the enjoyment it provides, for the satisfaction they find in doing it because it is oriented to a well- defined objective that is congruent with their own expectations".[5]

The professor's function was characterised by an attitude of listening that is underpinned with interventions that led students to reflect upon themselves, to think of themselves from a subjective reality. [6].

The figure 8 shows some luminaries that were exhibited in the event 2017 and they have different interpretations. For example, the meaning of journey of life -symbolised with the airplane-, the friendship's value represented with the fox and the little prince, the rose's symbol that reflects that each person is unique like the book said. However, these results was personal interpretations by the students and it not be assured that they will appropriate these virtues in the future.
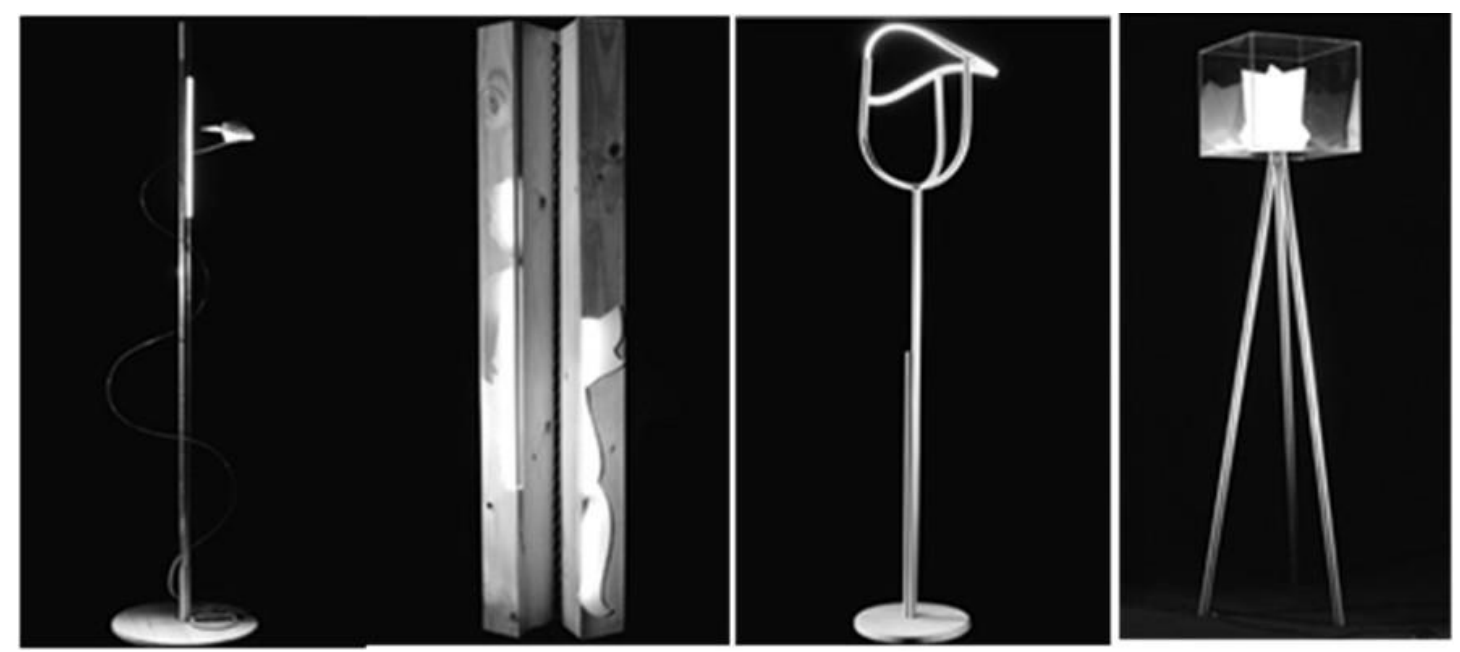

Figure 8. Examples of the luminaries inspired by the Little Prince.

\section{CONCLUSIONS}

The project inspired by the Little Prince in 2017 was a real challenge: The students would turn the intanginble: a feeling, a desire, a dream, a personal value into a material object: the luminarie. The challenge was to understand and live the experience of designing with meaning inpired by values of the book: The Little Prince. The students needed an intrinsic motivation to produce best results.

The professor's accompaniment was fundamental in this kind of exercise: This encouraged them to think about themselves and, based on that reflection, to create an idea and materialise it in a product.

This project was a risk and adventure, because the students approached on the subject of virtues and they could show them like a concept product, but was not a guarantee that they approved these values like human beings by themselves.

The exercise sought to transform the students internally by understanding that the act of designing must be a interactive process, in which they must have the ability to make decisions, use design tools, and reflect on human values. Likewise, the design of luminaire could trasnform students from a human standpoint, if they were able to understand the responsability when they designing with meaning and awareness. This kind of designing could have implications in the world that surrounds them, by efficiently using resources and improving people's quality life. 


\section{REFERENCES}

[1] Hiort af Hornas V. and Keitsch M. Questions of Value - Ethics in the Design Curriculum. In the 17th International Conference on Engineering and Product Design Education. Loughborough, September 2015, pp 208.

[2] Franco N. Atreverse a Pensar, un Camino hacia la Integridad, 2017. (Editorial EAFIT).

[3] Patiño L.F. and Franco N. Designing with Light and Meaning. A Design Project for Luminaries inspired by The Little Prince, by Antoine de Saint Exuspery, 2018 (Editorial EAFIT)

[4] Design Museum. ¿Cómo diseñar una lámpara?, 2016. (Gustavo Gilli)

[5] Marina J.A. Los Secretos de la Motivación, 2011 (Ariel)

[6] Lerner J. and Gil L. Metodología del Aprendizaje. 2006, pp. 111-112 (Fondo Editorial Universidad EAFIT).

[7] Pimienta J.H. Estrategias de Enseñanza Aprendizaje. Docencia Universitaria basada en Competencias, 2012. (Pearson) 